\title{
Some Conditions influencing the Fixation of Nitrogen by Azotobacter and the Growth of the Organism.
}

\author{
BY
}

\author{
FLORENCE A. MOCKERIDGE, B.Sc., A.K.C. \\ Layton Research Scholar at King's College, London.
}

$\mathrm{D}^{\mathrm{u}}$

URING the progress of some research upon the utilization of various organic substances as food material by Azotobacter, of which an account will appear in due course, considerable difficulty was experienced in obtaining and keeping pure liquid cultures of the organism. Other investigators appear to have encountered a similar difficulty, for many different nutrient media and methods of culture are recommended by various authors. Most of the solutions advocated by them were tested in turn, with such unsatisfactory results that it was at last deemed advisable to make a thorough examination of the behaviour of the organism in these different culture solutions, both in respect of the rapidity and purity of the growth, and the extent of fixation of nitrogen obtained per unit of the carbohydrate consumed. The work was undertaken in the first place solely for the author's convenience, in order to clear away these preliminary difficulties as a preparation for further research, but the results appear to be of sufficient importance to warrant publication, and are embodied in the following account, in the hope that they may be of use to other workers on the subject.

Undoubtedly the best method of obtaining a luxuriant growth in a short space of time is by the use of plate cultures in the manner advocated by Hoffmann and Hammer, in which the surface of a mannite-agar plate is covered with 5 or Io c.c. of a suspension of Azotobacter in 0.9 per cent. sodium-chloride solution. By this means a prolific growth is obtained uniformly over the whole surface of the plate, and, if the medium is sterile in the first place, no difficulty is experienced in keeping pure vigorous cultures on these agar plates. The trouble arose when liquid cultures were required, and it was necessary, in the first place, to arrive at some conclusion as to what are the optimum conditions with regard to alkalinity; and, in the second place, to decide which are the inorganic constituents of the nutrient medium which are necessary and beneficial to the organism, the

[Annals of Botany, Vol. XXVI. No. CIII. July, 1912.] 
best organic constituent having been accepted for the time being as mannite. Mme Krzemieniewski has shown that potassium, calcium, sulphur, magnesium, and phosphorus are all essential to the development of Azotobacter. Recent work by Omeliansky and Ssewerowa, and also by Remy and Rösing, has brought out the importance of iron, while Kaserer lays stress on the need for aluminium and silicon also; but further reference will be made to this work later.

The solutions, apart from those containing iron, aluminium, and silicon, which had been used with more or less success, practically resolve themselves into two classes: firstly, those in which neutralization of the acid potassium phosphate had been effected simply by the addition of excess of calcium carbonate; and, secondly, those in which the acidity had been neutralized by the addition of dilute sodium-hydrate solution, either to the whole culture solution, or to a solution of the phosphate made separately and afterwards added to the main bulk, the necessary calcium being supplied to the medium in the form of a small amount of a salt other than the carbonate. A combination of the two methods is found in the medium used by Ashby, who dissolves the phosphate separately, just neutralizes it with sodium hydrate, and, after the addition of this to the main portion of the solution, adds an excess of calcium carbonate. The solution used by Beijerinck consisted of:

$\begin{array}{lllll}\text { Tap water } & \cdot & \cdot & \cdot & \text { I,000 c.c. } \\ \text { Mannite } & \cdot & \cdot & \cdot & 20 \text { grm. } \\ \text { Di-potassium } & \text { phosphate } & \cdot & \cdot & 0.2 \\ \text { grm. }\end{array}$

and, having used this for purposes of experiment, he claims that Azotobacter will not, in pure culture, fix nitrogen. Chester points out that the medium is at fault, since no attempt is made to correct the acidity of the phosphate, and he reports that a good fixation of nitrogen has been obtained at the New Jersey Experiment Station on a medium consisting of the following :

\begin{tabular}{|c|c|c|}
\hline Tap water & • & I,O०० c.c. \\
\hline Mannite & & $15 \mathrm{grm}$. \\
\hline Di-potassium phosphate & • & $0.5 \mathrm{grm}$. \\
\hline Magnesium sulphate & & $0.2 \mathrm{grm}$ \\
\hline Calcium chloride & & $0.02 \mathrm{grm}$. \\
\hline
\end{tabular}

the whole being rendered alkaline by means of sodium hydrate. Many attempts have been made by the writer to obtain growths of Azotobacter chroococcum on this medium, with very little success; and when a surface film has developed at all, it has been very scanty, the best having been obtained in solutions which had been rendered just neutral by sodium hydrate, the presence of any excess, even in very small amounts, of the latter proving fatal to development. No determinations of the nitrogen- 


\section{Nitrogen by Azotobacter and the Growth of the Organism. 873}

fixation upon this medium were made, for failure to obtain any growth at all occurred so frequently as to prove that this solution was far from favourable for the development of the particular strain of Azotobacters concerned in this investigation. No good results could be obtained in any medium which did not contain an excess of calcium or magnesium carbonate; and, this having been decided, the chief remaining point to be considered in this connexion was the question as to whether the addition of sodium, either as the hydrate or in any other form, is beneficial to the organism; the fact that Azotobacter will grow and fix nitrogen without it proving that it is not necessary. Since the isolation of the organism from the soil in I90I by Beijerinck, many workers have devoted a considerable amount of time to a determination of the conditions under which the most luxuriant growth of vigorous Azotobacters can be obtained ; for the importance, from a practical, agricultural point of view, of a precise knowledge of these conditions cannot be over-estimated, and the more simple the culture solution which can be used, the better. As regards the elements supplied, apart from the sodium and the neutralizing agents, the solutions used, except for the recent work above mentioned, are all practically similar, so that the liquid medium hitherto used by Professor Bottomley in the Botanical Laboratory at King's College was tested as a type of those without sodium, against Ashby's solution representing those containing sodium salts. At the suggestion of Professor Bottomley, an investigation was also made to obtain some idea of the efficiency of basic slag as a substitute for calcium carbonate, of which further details will be given later.

When the questions of the relative merits of Bottomley's and Ashby's solutions, and of calcium carbonate and basic slag as neutralizing agents, were settled, there arose the problem as to what is the best quantity of nutrient solution to supply to ensure maximum fixation. The practical worker requires a maximum yield of combined nitrogen for the minimum expenditure of carbohydrate ; and it has been suggested that the activity of the organism varies inversely, to a certain extent, with the quantity of food material supplied, i. e. that when provided with a very small portion of food, the Azotobacter economizes, using the carbohydrate to the best advantage; so that under these conditions fixation is relatively greater than in a liberal supply of food material. Closely connected with this is the question as to whether the organism is able to utilize the last traces of carbohydrate in the medium as a source of energy for the fixation of nitrogen, or whether, as has also been suggested by various workers, after a certain period of time, while some of the carbohydrate originally supplied is still present in the solution, a process of auto-digestion sets in, nitrogen-fixation coming to an end for the time being. In the experiments described by different authors, amounts of nutrient solution ranging from Io to I,O00 c.c. have been employed, with concentrations of carbohydrate ranging from 0.1 to 2 
and even 5 per cent., whilst the cultures have been allowed to grow for widely divergent periods of time before analysis has been made of their contents. The results reported by different workers as to the amounts of nitrogen fixed appear to be somewhat conflicting, but they are not strictly comparable one with another, since Gerlach and Vogel have shown that the activity of the organism varies with the concentration of the carbohydrate, and with the age of the culture, which latter statement is borne out by the results obtained in the course of the present work.

Some attempt having been made to solve the foregoing problems, some consideration was given to the question of aeration. Considerable attention has been directed by various investigators to the discovery of some means of improving the aeration of organisms grown in liquid cultures. Freudenreich more particularly advocates the method of using gypsum plates, placed in Petri dishes and soaked in nutrient solution, and Krainski reports that he obtained the characteristic browning in from two to four days by the adoption of this method; while strips of gypsum placed in test-tubes containing some of the solution are favoured by other workers. For solid media, Koch recommends the use of large Petri dishes containing a thin layer of mannite-agar, and this method has been universally adopted in cases where it is suited to the special requirements of the occasion. Whatever be the vessels used for the production of liquid cultures, the use of a layer of nutrient solution as thin as is consistent with convenience is always recommended; and some workers, notably Hoffmann and Hammer, advocate the use of white quartz sand, which is shaken to one side of the flask, and forms a slope which rises well above the surface of the liquid. The use of these sand slopes proved to be by far the most efficient and convenient method of improving the aeration of the organisms in the course of the present work, for a suspension of the Bacteria could readily be obtained by adding water, well shaking the vessel, and allowing the sand to subside; while when required for analysis, the whole of the contents of the flask could most easily be transferred to a Kjeldahl flask by means of a jet of distilled water from a wash-bottle. Accordingly some attempt was made to obtain an idea of the extent of the superiority of this method over that of the ordinary liquid culture, as far as the fixation of nitrogen per unit of carbohydrate consumed was concerned.

In order to ascertain the best medium, as regards the inorganic constituents, for the growth of Azotobacter, a pure culture of the organism was first obtained on a mannite-agar plate. A colony was transferred by means of a sterilized platinum wire to about $3 \circ$ c.c. of sterile water contained in a large test-tube, which was then well shaken, to ensure a uniform distribution of the Bacteria. One cubic-centimetre of this suspension was transferred by means of a sterile pipette to each of the flasks to be used for the experiment, for the purposes of which three nutrient solutions were 


\section{Nitrogen by Azotobacter and the Growth of the Organism. 875}

used. The first was that which had hitherto been used for the isolation and growth of the organism by Professor Bottomley in the Botanical Laboratory at King's College, and consisted of:

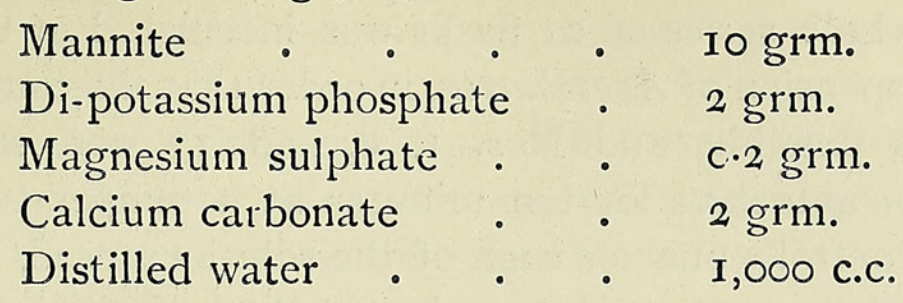

50 c.c. of this solution were put into each of seven 300 c.c. Jena glass Erlenmeyer flasks, which had previously been sterilized. The contents of the flasks were then boiled, 50 grm. of quartz sand, which had been previously washed, dried, screened, and recently ignited, were added, and each flask was plugged and allowed to cool, when the liquids were inoculated as described above. These flasks were numbered from $\mathrm{I}$ to 7.

The second solution employed was a modification of the first, suggested by Professor Bottomley, in which 0.2 per cent. of basic slag replaced the 0.2 per cent. of calcium carbonate. The acidity of the phosphate was neutralized by the lime in the slag, which, in addition, contained small amounts of the oxides of iron, manganese, magnesium, silicon, and aluminium, as shown in the analysis of the slag given later. The solution was thus made up as follows:

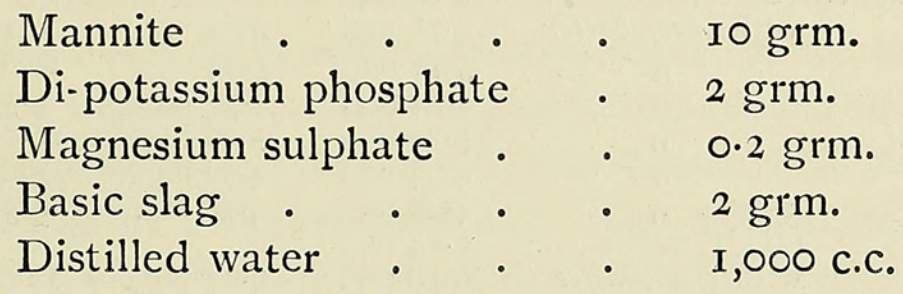

50 c.c. of this solution were then put into each of seven flasks, which were provided with sand slopes and otherwise treated in a manner exactly similar to that adopted with the first seven. These were numbered from 8 to 14 inclusive.

The third solution tried was that used by Ashby, but only Io grm. of mannite were used per litre, instead of 12 to $20 \mathrm{grm}$. as advised by Ashby, the alteration being made in order to render the solution comparable as regards the concentration of the carbohydrate with the preceding ones. The solution consisted of

$\begin{array}{lccc}\text { Mannite } & . & \text { Io grm. } \\ \text { Mono-potassium phosphate } & 0.2 \mathrm{grm} . \\ \text { Magnesium sulphate } & \cdot & \cdot & 0.2 \mathrm{grm} . \\ \text { Sodium chloride } & . & \cdot & 0.2 \mathrm{grm} . \\ \text { Calcium sulphate. } & . & . & 0.1 \mathrm{grm} . \\ \text { Calcium carbonate } & . & . & 5.0 \mathrm{grm} . \\ \text { Distilled water } & . & . & \text { I,000 c.c. }\end{array}$


The acid phosphate was dissolved separately and just neutralized by means of a decinormal sodium-hydrate solution before being added to the main bulk. The seven flasks used in this case were numbered from I 5 to $2 \mathrm{I}$ inclusive. The whole series of $2 \mathrm{I}$ flasks was inoculated at the same time with the same suspension of Azotobacter, in order that the conditions should be as uniform as possible, and Nos. I, 8, and I5 were sterilized, after inoculation, in the autoclave for ten minutes at a temperature of $135^{\circ} \mathrm{C}$. These served as controls, one for each of the solutions used, and by inoculating the flasks before sterilizing a knowledge of the actual fixation of nitrogen was arrived at, and not the nitrogen fixed plus the small amount of nitrogen supplied in the bacterial cells. The twenty-one flasks were then incubated at a temperature of $28^{\circ} \mathrm{C}$. for seven days, at the end of which period the contents of each were transferred by means of distilled water from a wash-bottle to round-bottomed flasks, to undergo analysis by the Kjeldahl process for their nitrogen content. The results of these analyses are given in the following table:

\section{TABLE I.}

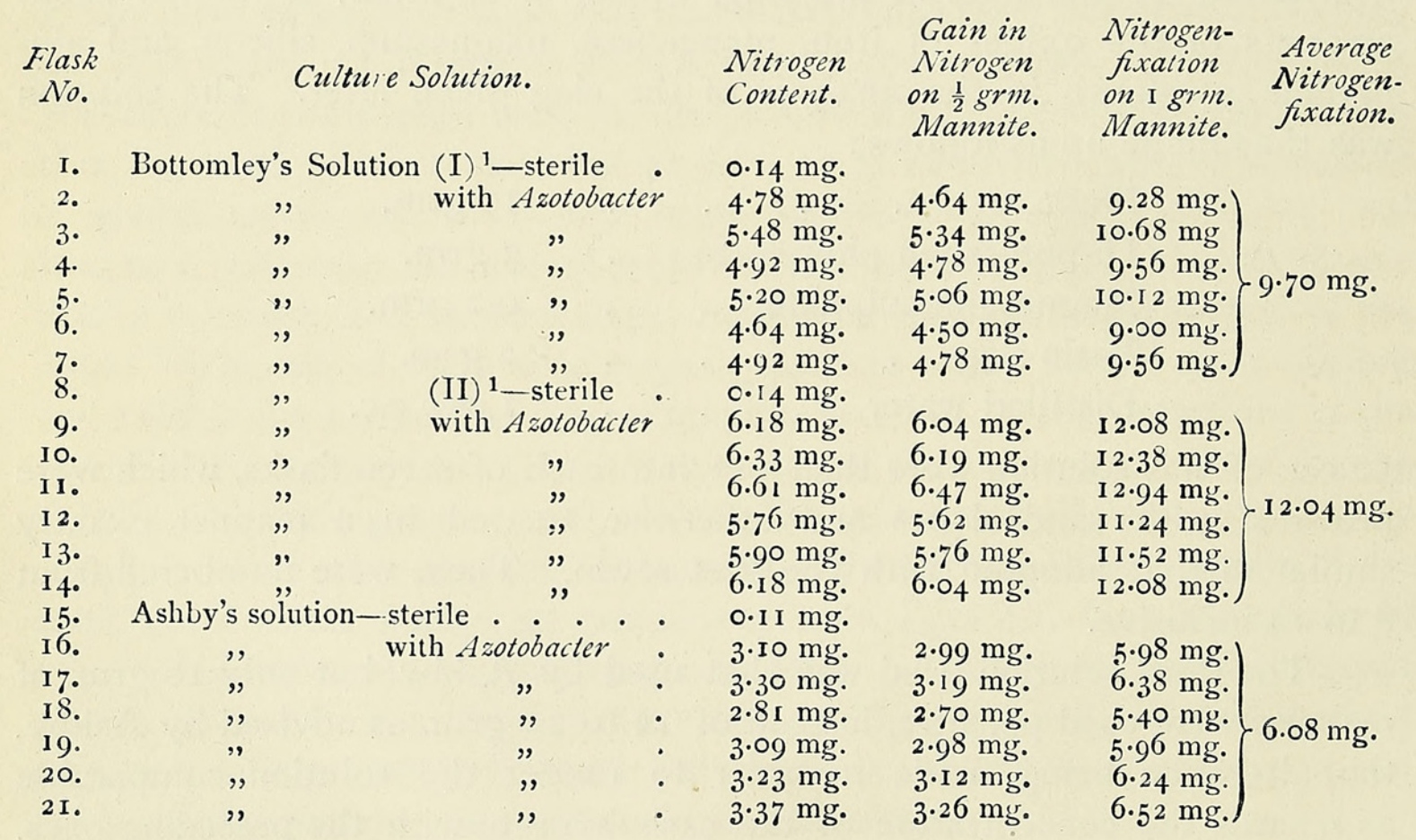

While the results show a very decided fixation of nitrogen in all the media, yet both of Bottomley's solutions appear to be better than Ashby's medium, and the presence of basic slag seems to have a beneficial effect. The fixations in each series appear to be fairly uniform among themselves, and are consistent with other results which have been obtained, so that, as a result of these determinations, Bottomley's solution (II),

1 'Bottomley's Solution (I)' is the solution containing calcium carbonate, while 'Bottomley's Solution (II)' is that containing basic slag. 
which contains basic slag as the neutralizing agent, has since been used in the Botanical Laboratory of King's College for isolation and growth of Azotobacters. This nutrient medium is one of the simplest which have been used, and by the addition of 2 per cent. of agar-agar, answers equally well for plate cultures.

One further point in connexion with the nutrient solution remained to be determined; i. e. whether, after complete neutralization of the acidity of the solution due to the phosphate, any further addition of basic slag produced a beneficial effect. Hoffmann and Hammer have shown that, so long as the liquid is neutral, increase in nitrogen-fixation does not follow upon increase of calcium carbonate in the medium ; but it seemed probable, since the presence of the slag appeared to give a distinct impetus to the fixation of nitrogen, that one or more of the constituents of the slag other than lime might have a tonic effect on the organism, which effect might be increased by the addition of a greater proportion of slag to the medium. The presence of 0.2 per cent. of the slag was sufficient to render the liquid neutral to litmus-paper, so five solutions were made up, each containing I per cent. mannite, 0.2 per cent. di-potassium phosphate, 0.02 per cent. magnesium sulphate, with the addition of $0.2,0.4,0.6,0.8$, and $\mathrm{I} \cdot 0$ per cent. of basic slag respectively. 50 c.c. of the solution containing 0.2 per cent. of slag were put into each of three flasks, which were provided with sand slopes and otherwise treated exactly as in the foregoing experiment. These flasks were numbered from I to 3, and, similarly, three flasks were used for each of the other four liquids, the total number being thus fifteen. Each one was then inoculated with the suspension of Azotobacter, and Nos. I, 4, 7, 10, and I3 were sterilized to serve as controls. The whole series was incubated for seven days at a temperature of $28^{\circ} \mathrm{C}$., and at the expiration of this time the contents of each flask were transferred to a Kjeldahl flask and analysed for their nitrogen content, with the following results :

TABLE II.

\begin{tabular}{|c|c|c|c|c|c|}
\hline $\begin{array}{l}\text { Flask } \\
\text { No. }\end{array}$ & $\begin{array}{l}\text { Proportion } \\
\text { of Slag. }\end{array}$ & $\begin{array}{l}\text { Nitrogen } \\
\text { Content. }\end{array}$ & $\begin{array}{l}\text { Fixation on } \\
\frac{1}{2} \text { grm. Mannite. }\end{array}$ & $\begin{array}{l}\text { Fixation on } \\
\text { I grm. Mannite. }\end{array}$ & $\begin{array}{l}\text { Average } \\
\text { Fixation. }\end{array}$ \\
\hline $\begin{array}{l}\text { I. } \\
2 .\end{array}$ & $\begin{array}{l}0.2 \% \\
0.2 \%\end{array}$ & $\begin{array}{l}0.55 \mathrm{mg} \text {. } \\
6.54 \mathrm{mg} .\end{array}$ & $5.99 \mathrm{mg}$. & I I. $98 \mathrm{mg}$. ) & \\
\hline 3. & $0.2 \%$ & $6.86 \mathrm{mg}$ & $6.3 \mathrm{I} \mathrm{mg}$. & I $2.62 \mathrm{mg}\}$. & $12.30 \mathrm{mg}$. \\
\hline 4. & $0.4 \%$ & $0.70 \mathrm{mg}$. & $6.86 \mathrm{mr}$ & $12.72 \mathrm{mo}$, & \\
\hline 6. & $0.4 \%$ & $8.12 \mathrm{mg}$. & $7 \cdot 4^{2} \mathrm{mg}$. & I $4.84 \mathrm{mg}$. & I $4.28 \mathrm{mg}$. \\
\hline $\begin{array}{l}7 . \\
8 .\end{array}$ & $\begin{array}{l}0.6 \% \\
0.6 \% \\
0.6 \%\end{array}$ & $\begin{array}{l}0.77 \mathrm{mg} . \\
6.5^{8} \mathrm{mg} . \\
6.30 \mathrm{mg} .\end{array}$ & $\begin{array}{l}5.81 \mathrm{mg} . \\
5.53 \mathrm{mg} .\end{array}$ & $\left.\begin{array}{l}\text { I I. } 62 \mathrm{mg} . \\
\text { I I.06 mg. }\end{array}\right\}$ & I I $\cdot 34 \mathrm{mg}$. \\
\hline Io. & $0.8 \%$ & $0.84 \mathrm{mg}$. & & & \\
\hline I I. & $0.8 \%$ & $6.02 \mathrm{mg}$. & $5.18 \mathrm{mg}$. & $10.36 \mathrm{mg}\}$. & $10.78 \mathrm{mg}$. \\
\hline $\begin{array}{l}\text { I2. } \\
\text { I3. }\end{array}$ & $\begin{array}{l}0.8 \% \\
1.0 \%\end{array}$ & $\begin{array}{l}6.44 \mathrm{mg} \text {. } \\
0.98 \mathrm{mg} \text {. }\end{array}$ & $5.60 \mathrm{mg}$ & I I. $20 \mathrm{mg}\}$. & $10.78 \mathrm{mg}$. \\
\hline I 4. & $1.0 \%$ & $7.56 \mathrm{mg}$. & $6.58 \mathrm{mg}$. & $13.16 \mathrm{mg}\}$. & I $3.02 \mathrm{mg}$. \\
\hline 15 . & I.O \% & $7 \cdot 4^{2} \mathrm{mg}$. & $6.44 \mathrm{mg}$ & I $2.88 \mathrm{mg})$. & \\
\hline
\end{tabular}


It appears from these figures that while a good fixation is obtained with 0.2 per cent. of slag, an even better one results from the use of 0.4 per cent. The addition of more than this, however, produces a perceptible, though not very considerable deterioration in nitrogen-fixing power, which effect increases with increase in the proportion of slag until i per cent. is reached, when the presence of this quantity appears to stimulate the organisms to greater activity than does the use of 0.6 or 0.8 per cent. The proportion of 0.4 per cent., however, obviously produces the most beneficial effects, probably on account of the stimulative effect of certain constituents of the slag; the addition of these substances in larger quantities than are contained in 0.4 per cent. being not only unnecessary, but harmful to the organism. The results obtained by the use of I per cent. of slag occasioned considerable surprise, but it seems possible that in this quantity just sufficient of another constituent, present in the slag in lesser proportion, has been added, to exert a second tonic effect, and overcome, to a certain extent, the depressing influence of over-doses of those elements to which the first stimulation was due. In order to test the truth of this hypothesis and to ascertain the effect of still larger proportions of slag, further series of experiments are now in progress, the results of which will be given as soon as possible. ${ }^{1}$ It is clear, however, that the effect of the slag is not limited, as is that of calcium carbonate, to a simple neutralization of acidity, but that certain constituents, though not essential to the growth of and fixation of nitrogen by Azotobacter, yet when added in the correct proportions, exert a beneficial influence on the activity of the organisms.

The question of the best liquid nutrient medium having been thus far settled, the next point to be ascertained was whether the Bacteria are able to utilize the last traces of carbohydrate food material present in the culture solution, or whether, when the solution of the nutrient has become sufficiently dilute, the process of auto-digestion before mentioned sets in, no further increase in the nitrogen content taking place. It is generally recognized that the carbohydrate in 50 c.c. of $I$ per cent. solution is practically used in seven days, so two series, each consisting of six flasks, were taken. These were numbered from 1 to 6 and from 7 to 12 inclusive. Each of the first six contained 50 c.c. of I per cent. Bottomley's solution, and each of the second six was supplied with 50 c.c. of I per cent. Ashby's solution, every one being provided with $50 \mathrm{grm}$. of sand to form a slope, and all being inoculated with I c.c. of the suspension of Azotobacter in sterile water. Nos. I and 7 were autoclaved at a temperature of $135^{\circ} \mathrm{C}$., and the whole series was incubated at $28^{\circ} \mathrm{C}$. The object of the experiment was to determine the fixation in each solution at the end of seven days, and also the fixation consequent on the consumption of the whole of the carbo-

1 Since the completion of this paper, these results have been obtained, and are given on p. $88_{5}$. 
hydrate. In order to prevent any vitiation of results by the abstraction of small quantities of the solution for examination for the presence of carbohydrate, the following method was adopted. One flask more than was required for analysis was included in each series, and since all the flasks had been supplied with exactly the same quantity of culture solution, and inoculated with the same amount of bacterial suspension, it was assumed that growth would take place at the same rate in each, and when the mannite in the extra flask had been consumed, it would also have disappeared from the others. Nos. 6 and 12 were used as these extra flasks, and at the end of the seventh day Nos. $1,2,3,7,8$, and 9 were analysed for their nitrogen content, while a drop was extracted from each of Nos. 6 and I2, evaporated to dryness on a glass slide, and examined microscopically for the crystals of mannite. Since the latter appeared to be present in both cases, Nos. 4, 5, 6, IO, II, and I2 were re-incubated for another day, when Nos. 6 and 12 were again examined. This time no crystals appeared in the drop extracted from No. 6 , so Nos. 4 and 5 were analysed, but No. I 2 still contained traces of the food-stuff. The remaining three of the series were accordingly re-incubated, and this process of testing No. I 2 each day for the mannite repeated until all the latter was consumed, when Nos. Io and I I were subjected to analysis. In this way some idea was obtained of the relation between the fixation in seven days upon 50 c.c. of the solution containing $\frac{1}{2}$ grm. of carbohydrate, and that upon the total $\frac{1}{2} \mathrm{grm}$. The results are shown in the following table:

\section{TABLE III.}

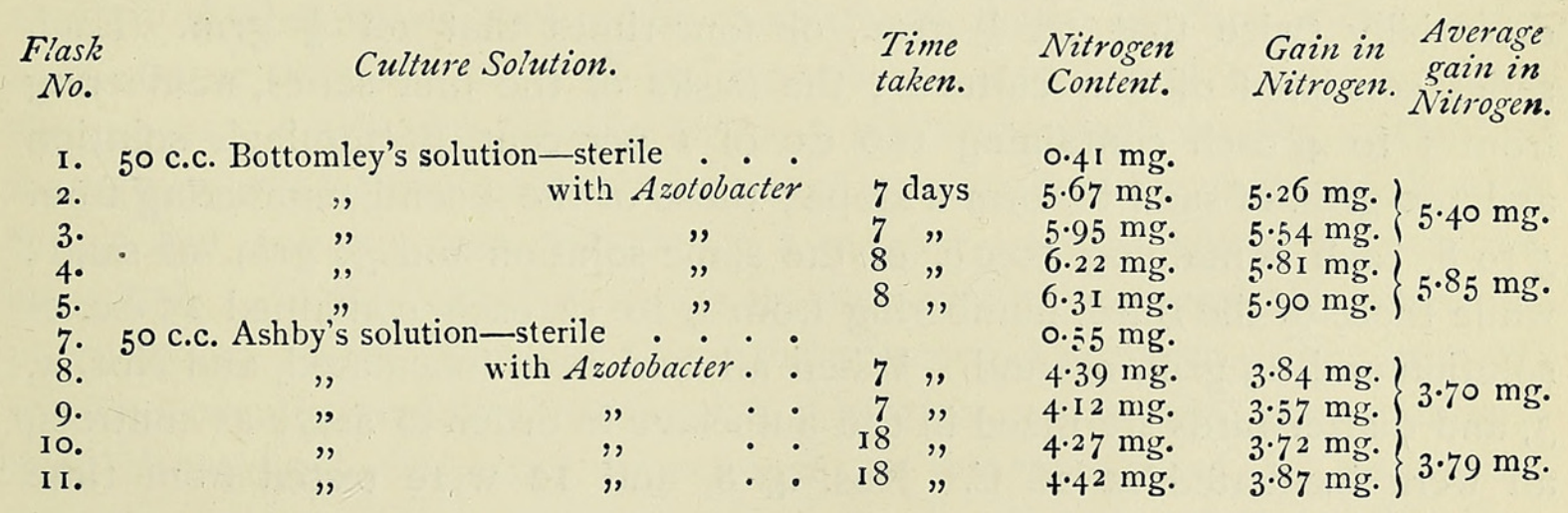

It is obvious that nitrogen-fixation was almost complete at the end of seven days in both series. In Bottomley's solution, however, the presence of mannite was manifested for only one day after this period, and the increase in nitrogen content for this day was nearly a half-milligramme; whilst in Ashby's solution, although the mannite was not completely used for eighteen days, yet the increase in nitrogen for the last eleven days of that period was scarcely beyond the range of experimental error in analysis. It is clear, how- 
ever, that even after the expiration of eighteen days there is no loss of nitrogen, and the evidence goes to show that the organisms are capable of utilizing the last traces of carbohydrate supplied to them, and, under the most favourable conditions, are able to continue the process of nitrogen-fixation until the food supply is exhausted. Exactly why the organisms should not have shown greater activity as regards the fixation of nitrogen in the cultures in Ashby's medium which had been left to grow for eighteen days is not clear, unless it be that the accumulation of certain products, either of partial decomposition of the mannite, or of excretion of the Azotobacter, or both, may have, in this rather less favourable medium, put an end to the nitrogenfixing activity of the organism for the time being. Upon inoculation of a fresh portion of the culture solution with Azotobacter from flask No. I2 a good and strong growth was obtained, so that evidently the organisms were in a perfectly healthy condition. Since these results have been obtained, an account of an investigation conducted by Koch and Leydell has come to hand, in which they state that nitrogen-fixation comes to an end after five to eight days, the remainder of the carbohydrate being utilized for respiration and other purposes. This would account for the presence of carbohydrate for eighteen days, during the last eleven of which no fixation of nitrogen took place in Ashby's medium, but under the best conditions Azotobacter appears to fix nitrogen vigorously while the carbohydrate lasts.

Three series of cultures were taken in order to determine whether, in the same percentage solution, the fixation of nitrogen is strictly proportional to the amount of carbohydrate consumed; i. e. whether the increase in nitrogen consequent upon the consumption of $\mathrm{I}$ grm. of mannite is essentially twice that on $\frac{1}{2} \mathrm{grm}$., or four times that on $\frac{1}{4} \mathrm{grm}$. Each series consisted of four cultures; the flasks of the first series, numbering from I to 4, each containing Ioo c.c. of I per cent. Bottomley's solution and $100 \mathrm{grm}$. of sand to form a slope; those of the second, numbering from 5 to 8 , each containing 50 c.c. of the same solution and $50 \mathrm{grm}$. of sand; while those of the third, numbering from 9 to 12 , each contained 25 c.c. of solution and $25 \mathrm{grm}$. of sand. When all had been inoculated, and Nos. I, 5 , and 9 afterwards sterilized in the autoclave in order to serve as controls, all were incubated at $28^{\circ} \mathrm{C}$. Nos. 4,8 , and 12 were tested from time to time for the presence of mannite, by evaporating a drop to dryness and examining for the crystals, and when one of these cultures no longer showed evidence of the presence of carbohydrate, the contents of the three remaining flasks of the series were analysed for their combined nitrogen, with the following results : 
Nitrogen by Azotobacter and the Growth of the Organism. 881.

\section{TABLE IV.}

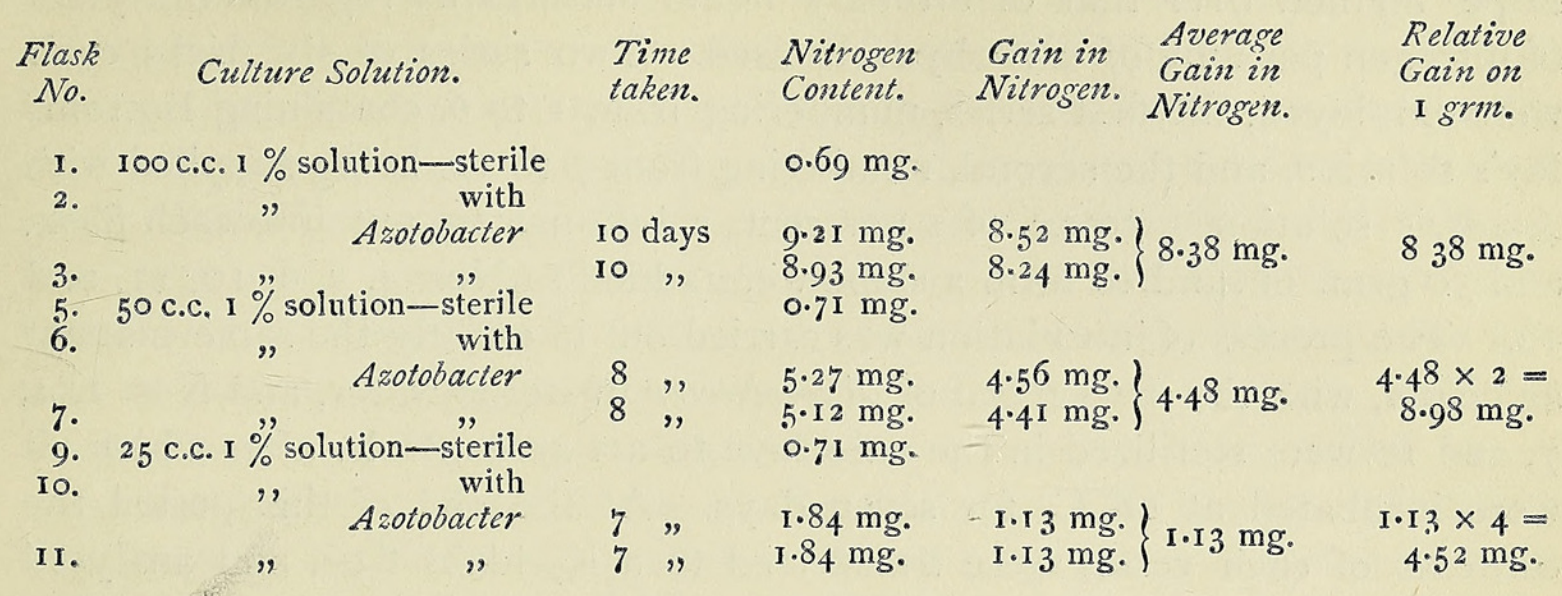

The flasks used were all of the same size, namely Erlenmeyer flasks of 300 c.c. capacity; hence the depth of the liquid, and consequently the aeration, varied with the quantity of solution supplied. It follows that the organisms in the 50 c.c. cultures obtained a better aeration than those in the 100 c.c., and this fact probably accounts for the slightly greater nitrogen-fixation, relatively, in the former than in the latter. Directly opposed to this is the comparatively small increase in the 25 c.c. cultures, though the organisms in this case possessed the greatest advantage as regards aeration. It is a well-known fact, however, that when supplied with soluble nitrogen, Azotobacter does not fix until this available nitrogen has been consumed, so the very small fixation in the 25 c.c. cultures is probably explained by the assumption that the Bacteria first of all utilize the small amount of nitrogen present in the medium, as shown by the control, using at the same time a portion of the mannite as a source of energy. When the process of nitrogen-fixation began, a relatively much smaller amount of mannite would be available as a source of energy in these cultures than in the 50 and 100 c.c. ones, and hence a smaller gain in nitrogen would be expected. All the materials used were supposed to be chemically pure, but every control so far examined shows the presence of nitrogen. The growths were apparently perfectly healthy, but it is fairly evident that the organisms used throughout the series were more or less weakened by continued growth under artificial conditions, since the fixation per gramme of carbohydrate consumed amounted to only between 8 and $9 \mathrm{mg}$., while in the earlier part of the work the organisms originally obtained from the same source gave fixations amounting to $\mathrm{I} 4 \mathrm{mg}$. However, Hoffmann and Hammer obtained good fixations in 25 c.c. of I per cent. solution, so that, when multiplied by four, their results gave fixations of $14.40 \mathrm{mg}$. on I grm. carbohydrate used-results which are not comparable with any of those obtained in 25 c.c. cultures in the course of the present work. 
In connexion with the question of aeration, some experiments were started to obtain some idea of the extent of the superiority of the sandslope method over that of ordinary liquid cultures as regards the yield of nitrogen per unit of carbohydrate used. Two series of six flasks each were employed, the first series, numbering from $\mathrm{I}$ to 6 , containing Bottomley's solution, and the second, numbering from 7 to 12 , being supplied with Ashby's solution. 50 c.c. of I per cent. solution were put into each flask, and $50 \mathrm{grm}$. of sand to form a slope were added to Nos. 4, 5, 6, IO, I I, and 12. The process of inoculation was carried out in exactly the same manner as before, with the suspension of Azotobacter in sterile water, and Nos. 1, 4, 7 , and so were sterilized in the autoclave to act as controls, after which all were incubated at $28^{\circ} \mathrm{C}$. for seven days. At the end of this period the contents of each vessel were transferred to a Kjeldahl flask and analysed for its nitrogen content, the results being as follows :-

\section{TABLE V.}

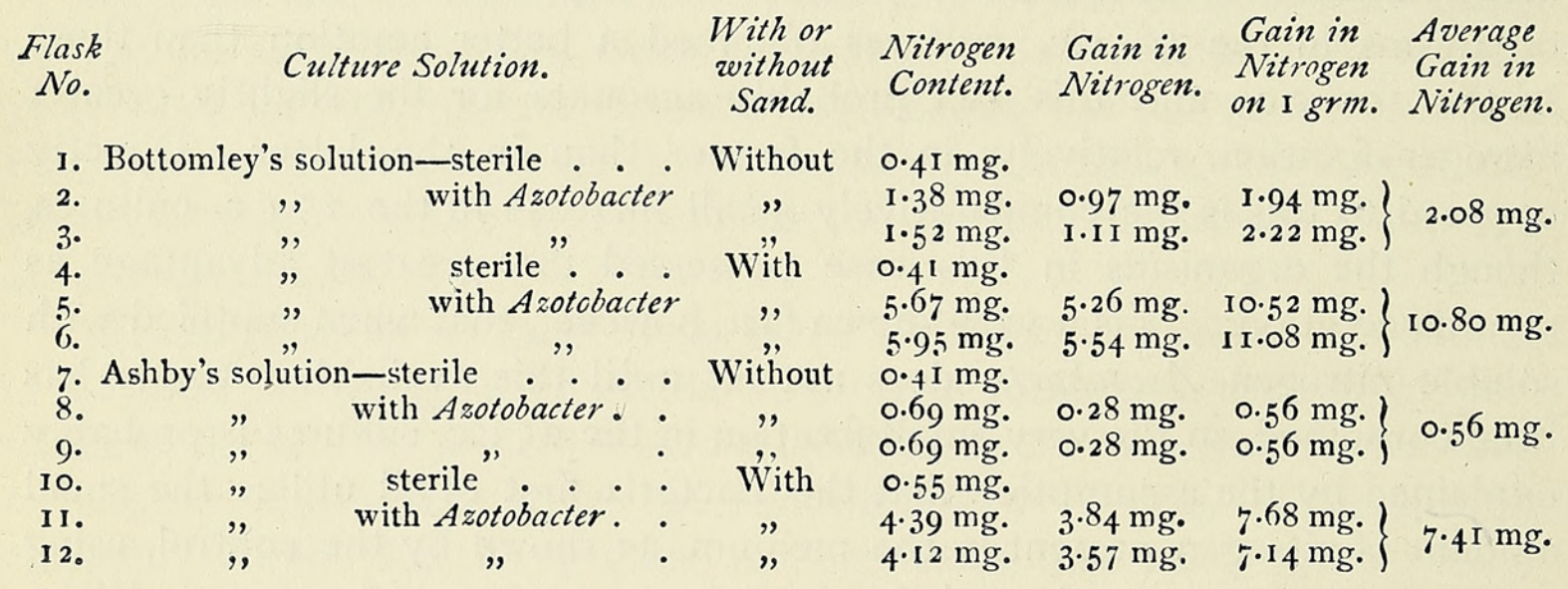

The effect of the increased aeration due to the sand slope is made very clear by these figures, and the difference between the simple liquid culture, and that on a sand slope, in rapidity of growth was equally apparent to the eye. On the sand slopes, the gelatinous growth appeared earlier, grew more rapidly, and darkened much more quickly than did that on the liquid. On the sand-slope cultures in Bottomley's solution, the film of Azotobacter appeared over the whole surface on the third day; its formation was deferred until the fifth day in the sand-slope cultures in Ashby's medium and in the ordinary cultures without sand in Bottomley's solution, while in Ashby's liquid cultures no perceptible growth occurred, and the fixation of nitrogen, as shown in the above table, was very slight. The effect on the rapidity of growth of the increased aeration due to the sand was very strikingly shown at the same time by some cultures grown on ethyl alcohol. When an ordinary liquid medium was inoculated, growth took place very slowly, the film appearing over the surface only after the 


\section{Nitrogen by Azotobacter and the Growth of the Organism. 883}

lapse of about ten days, while at the end of the same period a prolific growth was apparent in the vessels containing the sand slopes, the particles of the white quartz sand which had been used having become almost black, due to the darkening of the film of Azotobacter which thus evidently covered each grain. The better aerobic condition maintained by the presence of the sand was also effective in assisting to the purity of the cultures, any anaerobic Clostridium with which they had become contaminated developing here with much greater difficulty than under the less aerated conditions found in the ordinary liquid cultures. Clostridium, where present, was also seen to develop decidedly better in Ioo c.c. cultures than in 50 c.c. ones, the deeper layers of the larger volume being obviously more suited to its requirements than those of the smaller culture. The presence of sodium also seemed to favour the growth of these butyric organisms, and more particularly was this evident in the New Jersey medium, where, if the feeble growth of Azotobacter became contaminated with Clostridium, the latter developed vigorously, while the further development of the former was inhibited. This is due to the fact that no excess of the neutralizing agent was present in the medium, to correct the acidity of the products of vital activity of Clostridium, the accumulation of acid products proving fatal to Azotobacter.

\section{CONCLUSIONS.}

The conclusions which have been arrived at as a result of this investigation appear to be of some importance in connexion with the production of large quantities of vigorous Azotohacters, especially when they are required for soil inoculation, in which case the strongest possible cultures are desirable. The main points are as follows :

In the first place, the presence in the medium of an excess of calcium, or magnesium carbonate, or basic slag, as a neutralizing agent, is more advantageous than that of sodium hydrate; and the former substances not only assist the rapidity of the growth, but also help to maintain its purity.

The figures obtained show clearly that the presence of sodium salts is not only unnecessary, but exerts a depressing influence on the activity of Azotobacter as regards the fixation of nitrogen. The beneficial effect of the sodium-chloride solution in inoculating agar plates is due to the fact that this liquid is isotonic with the cell-contents, a solution of similar concentration of many other salts answering the purpose equally well.

Basic slag is an excellent substitute for precipitated chalk as a neutralizing agent in the nutrient medium, and it evidently also contains ingredients which exert a tonic effect upon the organism, increasing its activity in connexion with nitrogen-fixation by as much as 23 per cent. Exactly which of the constituents of the slag have this influence is not known, but probably the iron and manganese present are the most important 
in this respect. Appended is an analysis of the slag which, together with samples of the material, was furnished by the courtesy of the Manager of the Chemical Works-late H. and E. Albert.

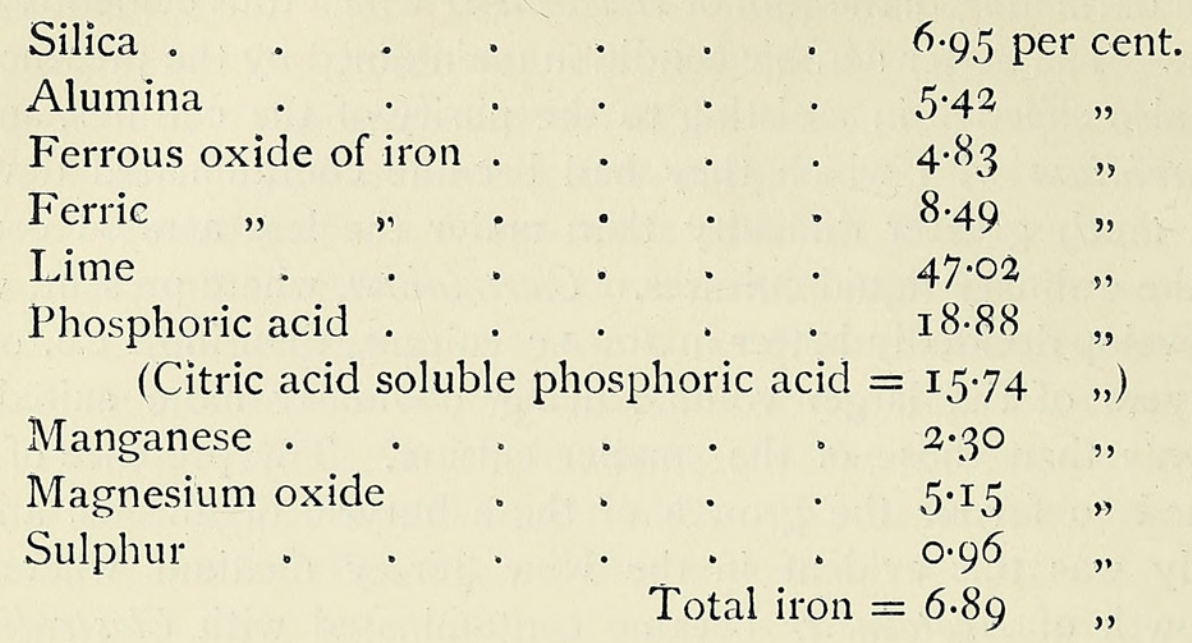

The proportion of slag required to induce a maximum fixation of nitrogen is 0.4 per cent.

This solution, with basic slag as the neutralizing agent, contains all the ingredients which Mme Krzemieniewski states are essential to the development of Azotobacter, besides the iron which Omeliansky and Ssewerowa, and more particularly Remy and Rösing, find to be so important, and the aluminium and silicon which the experiments of Kaserer prove to be so beneficial. Mme Krzemieniewski states that the minimum amounts of the elements requisite for the consumption of $\mathrm{I}$ grm. of dextrose are potassium $0.38 \mathrm{mg}$., calcium $0.36 \mathrm{mg}$., magnesium $0.35 \mathrm{mg}$., phosphorus $2.46 \mathrm{mg}$., and sulphur more than $0.49 \mathrm{mg}$. These requirements are fulfilled by the medium the use of which is here advocated, and the results obtained appear to be in accordance with those of the investigators mentioned.

Although nitrogen-fixation can, and does, under favourable conditions, proceed until the food material is completely exhausted, yet the most active fixation of nitrogen in the small 50 c.c. cultures used in the laboratory is obtained during the course of the first week, possibly owing to some depressing influence which the accumulation of the products of their vital activity may exert upon the organisms.

The yield of combined nitrogen per unit of carbohydrate consumed is apparently not influenced by the depth of the layer of liquid to such an extent as to warrant the use in all cases of the minimum quantity, and, for the purposes of experiment in the laboratory, a volume of 50 c.c. of solution in a 300 c.c. Erlenmeyer flask gives a layer sufficiently well aerated to ensure a good fixation. The best results are evidently not obtained by the supply of only very small amounts of carbohydrate food material, but, once a good growth is obtained, the yield of nitrogen appears to be practically proportional to the amount of food supplied. The use of fairly thin layers of 
Nitrogen by Azotobacter and the Growth of the Organism. 885

liquid is, however, to be advocated as assisting in the aeration of the culture, and thus inhibiting, to some extent, the growth of any contaminating Clostridium.

The use of sand slopes, as a means of increasing the surface, and therefore the supply of oxygen and nitrogen to the organisms, is to be strongly recommended, the adoption of this method resulting in a more rapid, vigorous, and healthy growth, giving a much greater increase in nitrogen in a given space of time, and being much more free from contamination by anaerobic organisms than is the method of ordinary liquid cultures.

The use of the sand-slope method of culture, with Bottomley's medium in volumes of 50 c.c., results in the fixation of $\mathrm{I} 4 \mathrm{mg}$. of nitrogen per gramme of mannite consumed, when the most vigorous organisms are used for purposes of inoculation.

Another important result of the present investigation is the confirmation which it gives to the statement of Gerlach and Vogel, that the nitrogenfixing activity of Azotobacters decreases as their age increases, since in the latter part of the work, when the organisms had presumably become weakened by successive subculture under artificial conditions, they were able to fix only between 8 and $9 \mathrm{mg}$. of nitrogen, their yield in the earlier part of the work having been $\mathrm{I} 4 \mathrm{mg}$. per gramme of carbohydrate consumed.

In conclusion, my grateful thanks are due to Professor W. B. Bottomley for the many helpful suggestions given and the kindly interest maintained during the progress of the work.

\section{ADDENDUM.}

As a result of the unexpected fixation of nitrogen obtained on $\mathrm{I}$ grm. of mannite in a medium containing I per cent. of slag, nine solutions were made up in order to test the effect of increasing proportions of this neutralizing agent. These solutions each contained I per cent. mannite, 0.2 per cent. di-potassium phosphate, 0.02 per cent. magnesium sulphate, with the addition of $\mathrm{I} \cdot 2, \mathrm{I} \cdot 4,2 \cdot 0,2 \cdot 8,4 \cdot 0,5 \cdot 0,6 \cdot 0,8 \cdot 0$, and $10 \cdot 0$ per cent. of basic slag respectively. 50 c.c. of the solution containing $\mathrm{I} \cdot 2$ per cent. were put into each of three flasks, and $5 \circ \mathrm{grm}$. of sand were added to form a slope. These flasks were numbered from I 6 to 18 , and, similarly, three flasks were used for each of the other solutions, the total number being thus twenty-seven. Nos. 16, 19, 22, $25,28,31,34,37$, and 40 were autoclaved to serve as controls, and the whole series was incubated for seven days at a temperature of $28^{\circ} \mathrm{C}$. They were then analysed for their nitrogen content, and the total results obtained with the varying proportions of slag are as follows: 


\begin{tabular}{|c|c|c|c|c|c|}
\hline $\begin{array}{l}\text { Flask } \\
\text { No. }\end{array}$ & $\begin{array}{c}\text { Proportion } \\
\text { of Slag. }\end{array}$ & $\begin{array}{l}\text { Nitrogen } \\
\text { Content. }\end{array}$ & $\begin{array}{l}\text { Fixation on } \\
\frac{1}{2} \text { grm. Mannite. }\end{array}$ & $\begin{array}{l}\text { Fixation on } \\
\text { I grm. Mannite. }\end{array}$ & $\begin{array}{l}\text { Average } \\
\text { Fixation. }\end{array}$ \\
\hline I. & $0.2 \%$ & $0.55 \mathrm{mg}$. & & & \\
\hline 2. & $0.2 \%$ & $6.54 \mathrm{mg}$ & 5.99 mg. & I I. $9^{8} \mathrm{mg}$. ) & \\
\hline 3. & $0.2 \%$ & $6.86 \mathrm{mg}$ & $6 \cdot 3 \mathrm{I} \mathrm{mg.}$ & I $2.62 \mathrm{mg}\}$. & $12 \cdot 30 \mathrm{mg}$ \\
\hline 4. & $0.4 \%$ & $0.70 \mathrm{mg}$. & & & \\
\hline $\begin{array}{l}5 . \\
6 .\end{array}$ & $\begin{array}{l}0.4 \% \\
0.4 \%\end{array}$ & $\begin{array}{l}7 \cdot 56 \mathrm{mg} . \\
8 \cdot 12 \mathrm{mg} .\end{array}$ & $\begin{array}{l}6.86 \mathrm{mg} \text {. } \\
7.42 \mathrm{mg} .\end{array}$ & $\left.\begin{array}{l}\text { I } 3.72 \mathrm{mg} . \\
\text { I } 4.84 \mathrm{mg} .\end{array}\right\}$ & $\mathrm{I}_{4} \cdot 28 \mathrm{mg}$. \\
\hline $\begin{array}{l}7 . \\
8 .\end{array}$ & $\begin{array}{l}0.6 \% \\
0.6 \%\end{array}$ & $\begin{array}{l}0.77 \mathrm{mg} \text {. } \\
6.58 \mathrm{mg} .\end{array}$ & $5 \cdot 8 \mathrm{I} \mathrm{mg}$ & I I.62 mg. & \\
\hline 9. & $0.6 \%$ & $6.30 \mathrm{mg}$ & $5.53 \mathrm{mg}$. & I I.06 $\mathrm{mg}$. & I I $34 \mathrm{mg}$. \\
\hline 10. & $0.8 \%$ & $0.84 \mathrm{mg}$ & & & \\
\hline I I. & $0.8 \%$ & $6.02 \mathrm{mg}$ & 5. I8 mg. & $10.36 \mathrm{mg}$. & \\
\hline I 2. & $0.8 \%$ & $6.44 \mathrm{mg}$ & $5.60 \mathrm{mg}$ & I I. $20 \mathrm{mg}\}$. & $10 \%$ \\
\hline I3. & $1.0 \%$ & $0.98 \mathrm{mg}$. & & & \\
\hline I 4. & $I \cdot 0 \%$ & $7 \cdot 56 \mathrm{mg}$ & $6.58 \mathrm{mg}$ & I3.16 mg. & $\mathrm{I} 3.02 \mathrm{mg}$ \\
\hline I 5. & $\mathrm{I} \cdot 0 \%$ & $7 \cdot 42 \mathrm{mg}$ & $6.44 \mathrm{mg}$ & I $2.88 \mathrm{mg} \cdot\}$ & 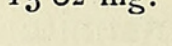 \\
\hline 16. & $\mathrm{I} \cdot 2 \%$ & $0.28 \mathrm{mg}$. & & & \\
\hline 17. & $\mathrm{I} \cdot 2 \%$ & $5^{\cdot 87} \mathrm{mg}$. & $5.59 \mathrm{mg}$. & I I. I $8 \mathrm{mg}$. & $\mathrm{I} \mathrm{I} \cdot \mathrm{I} 8 \mathrm{mg}$. \\
\hline 18. & $1 \cdot 2 \%$ & $5.87 \mathrm{mg}$. & $5^{\circ} 59 \mathrm{mg}$ & II. I8 mg. ) & \\
\hline $\begin{array}{l}19 . \\
20 .\end{array}$ & $1.4 \%$ & $0.28 \mathrm{mg}$. & $5.36 \mathrm{mg}$ & & \\
\hline $2 \mathrm{I}$ & $\mathrm{I} \cdot 4 \%$ & $5.50 \mathrm{mg}$ & $5.22 \mathrm{mg}$ & $\mathrm{I0.44} \mathrm{mg}$. & $10.58 \mathrm{mg}$. \\
\hline 22. & $2.0 \%$ & $0.71 \mathrm{mg}$. & 520.50 & 244.40 & \\
\hline 23. & $2.0 \%$ & $5^{\circ} 53 \mathrm{mg}$. & $4.82 \mathrm{mg}$ & $9.64 \mathrm{mg}$. ? & \\
\hline 24 . & $2.0 \%$ & $5.90 \mathrm{mg}$. & $5^{\circ} \mathrm{I} 9 \mathrm{mg}$. & $\left.\mathbf{1 0} 3^{8} \mathrm{mg}.\right\}$ & $10.01 \mathrm{mg}$ \\
\hline 25. & $2.8 \%$ & $0.71 \mathrm{mg}$. & & & \\
\hline 26. & $2.8 \%$ & $5.28 \mathrm{mg}$ & $4.57 \mathrm{mg}$ & $9^{\circ} \mathrm{I} 4 \mathrm{mg}$. & $0.0 \quad-1$ \\
\hline 27 & $2.8 \%$ & $5 \cdot 14 \mathrm{mg}$ & $4.43 \mathrm{mg}$ & $8 \cdot 86 \mathrm{mg} \cdot \mathrm{l}$ & $900 \mathrm{mg}$ \\
\hline 28. & $4.0 \%$ & $0.64 \mathrm{mg}$ & & & \\
\hline 29. & $4.0 \%$ & $5.43 \mathrm{mg}$. & $4.79 \mathrm{mg}$ & $9.58 \mathrm{mg} \cdot\}$ & $9.29 \mathrm{mg}$. \\
\hline 30. & $4.0 \%$ & 5. I 4 mg. & $4.50 \mathrm{mg}$ & $9.00 \mathrm{mg} \cdot \mathrm{J}$ & \\
\hline $3 \mathrm{I}$. & $5.0 \%$ & $0.74 \mathrm{mg}$. & & $8.80 \mathrm{mg})$ & \\
\hline $\begin{array}{l}52 \cdot \\
33\end{array}$ & $5.0 \%$ & $\begin{array}{l}5^{\circ} 14 \mathrm{mg} \text {. } \\
5 \cdot 28 \mathrm{mg} \text {. }\end{array}$ & $\begin{array}{l}4.40 \mathrm{mg} \text {. } \\
4.54 \mathrm{mg} \text {. }\end{array}$ & $0.08 \mathrm{mg}$. & $8.94 \mathrm{mg}$. \\
\hline .34 & $6.0 \%$ & $0.28 \mathrm{mg}$. & 454.20 & 900110.1 & \\
\hline 35. & $6.0 \%$ & $2.86 \mathrm{mg}$ & $2.58 \mathrm{mg}$ & $5 \cdot 16 \mathrm{mg} \cdot\}$ & $4.87 \mathrm{mo}$ \\
\hline 36. & $6.0 \%$ & $2.57 \mathrm{mg}$ & $2 \cdot 29 \mathrm{mg}$ & $4 \cdot 5^{8} \mathrm{mg} \cdot \int$ & 40 \\
\hline $\begin{array}{l}37 \\
38\end{array}$ & $\begin{array}{l}8.0 \% \\
8.0 \%\end{array}$ & $\begin{array}{l}0.43 \mathrm{mg} \text {. } \\
\mathrm{I} \cdot 86 \mathrm{mg} \text {. }\end{array}$ & $I \cdot 431$ & $2.86 \mathrm{mg}$. ) & \\
\hline 39. & $8.0 \%$ & $\mathrm{I} \cdot 57 \mathrm{mg}$. & $\mathrm{I} \cdot \mathrm{I} 4 \mathrm{mg}$. & $2 \cdot 28 \mathrm{mg} \cdot\}$ & $2.57 \mathrm{mg}$. \\
\hline 40. & $10.0 \%$ & $0.7 \mathrm{I} \mathrm{mg}$. & & & \\
\hline $4 \mathrm{I}$ & $10.0 \%$ & $0.64 \mathrm{mg}$. & - & - & \\
\hline $4^{2}$. & $10.0 \%$ & $0.7 \mathrm{I} \mathrm{mg}$ & & - & \\
\hline
\end{tabular}

It appears from these results that a proportion of 0.4 per cent. of basic slag has the most beneficial effect upon the activity of the organisms. Their nitrogen-fixing power declines when more than 0.4 per cent. is used, but receives a further stimulation in a medium containing $I$ per cent. A steady decrease in nitrogen-fixation follows upon increase in the proportion of slag above I per cent., until 5 per cent. is reached, when it begins to fall rapidly and is rendered impossible in a medium containing ro per cent.

These observations appear to lend support to the hypothesis put forward in a previous paragraph, that the effect of basic slag is not limited to a simple neutralization of acidity, but that there are at least two constituents, probably iron and manganese, present in the slag in different proportions, which exert a tonic influence upon the organisms; the maximum effect of the one being obtained in a proportion of 0.4 per cent., the other being most efficacious in a medium containing $\mathrm{I} \cdot \mathrm{O}$ per cent. 


\section{LITERATURE CITED.}

As'hby, S. F. : Journ. Agric. Science, ii, 1907-8, p. 54.

BeIJerinck : Centralbl. f. Bakt., vii, I90I, p. 56 r.

Chester, G. K. : New Jersey State Expt. Station Report, I904.

FREUDENREICH, ED. von : Centr. f. Bakt., ix, I902, p. 5 I 4.

Gerlach and Vogel : Centr.f. Bakt., viii, I902, p. 669 ; ix, p. $\delta \mathrm{I} 7$; x, I903, p. 636 .

Hoffmann, C., and Hammer, B. W.: Univ. of Wisconsin, Agric. Expt. Station Research Bulletin, xii, June Igro.

Kaserer, Hermann : Ber. d. Deutsch. Bot. Gesellsch., xxviii, I910, pp. 208-1 2.

Koch, A. : Lecture before Econ. Soc. of Saxony, Dec. I903. Article in Lafar's Handb. der technischen Mykologie, 2nd Ed., 1904. , and Seydell, Siegfried : Centr. f. Bact., xxxi, 19II, pp. 570-7.

Krainski, A.: Centr. f. Bakt., xx, I908, p. 725.

Krzemieniewski, H. (Mme) : Bull. Acad. Sci. Cracovie, i910, pp. 376-413.

Omeliansky, W. I., and Ssewerowa, O. P.: Centr. f. Bakt., xxviii, I9II, p. 645.

Remy, TH., and Rös:NG, G. : Centr. f. Bakt., xxx, I9I I, p. 378 . 


\section{$2 \mathrm{BHL}$ Biodiversity Heritage Library}

Mockeridge, Florence A. 1912. "Some conditions influencing the fixation of nitrogen by Azotobacter and the growth of the organism." Annals of botany 26, 871-887. https://doi.org/10.1093/oxfordjournals.aob.a089420.

View This Item Online: https://www.biodiversitylibrary.org/item/236930

DOI: https://doi.org/10.1093/oxfordjournals.aob.a089420

Permalink: https://www.biodiversitylibrary.org/partpdf/319933

\section{Holding Institution}

Smithsonian Libraries

\section{Sponsored by}

Biodiversity Heritage Library

\section{Copyright \& Reuse}

Copyright Status: Not in copyright. The BHL knows of no copyright restrictions on this item.

This document was created from content at the Biodiversity Heritage Library, the world's largest open access digital library for biodiversity literature and archives. Visit BHL at https://www.biodiversitylibrary.org. 